\title{
Papel da igreja na construção de capital social: caso da região oeste de Santa Catarina
}

\section{Role of the church in building social capital: case of the western region of the brazilian state of Santa Catarina}

Papel de la iglesia en la construcción de capital social: caso de la región oeste de Santa Catarina

\author{
Volmir Rabaioli ${ }^{1}$ \\ Olivier François Vilpoux ${ }^{2}$
}

${ }^{1}$ Doutorando do Programa de Ciências Ambientais e Sustentabilidade Agropecuária da Universidade Católica Dom Bosco; Mestre em Desenvolvimento Local- Linha de Pesquisa: Desenvolvimento local: sistemas produtivos, inovação, governança; PósGraduado em Engenharia de Produção e em Gestão de Operações e Logística; Bacharel em Administração de Empresas com ênfase em Comércio Exterior; Professor do Instituto Federal do Mato Grosso do Sul- Campus Coxim. Bolsista do Conselho Nacional de Desenvolvimento Científico e Tecnológico (CNPq). E-mail: rabaiole@hotmail.com

${ }^{2}$ Graduado em Engenharia Agrônomica no Institut Supérieur Dagriculture, na França, mestrado em Administração no Institut de Gestion Internationale en Agro Alimentaire e doutorado em Administração no Institut National Polythecnique de Lorraine. Atualmente é professor pesquisador da Universidade Católica Dom Bosco (UCDB), Professor do Programa de Mestrado em Desenvolvimento Local (UCDB) e do Doutorado em Administração da Universidade Federal de Mato Grosso do Sul (UFMS).

E-mail:vilpoux@ucdb.br 
Resumo: A pesquisa analisa o papel da Igreja na construção do Capital Social da região oeste de Santa Catarina. As informações foram obtidas em pesquisas bibliográfica, documental e de campo. A Igreja atuou na formação das colônias da região e instituiu um modelo de vida comunitária e convívio social que atendesse seus interesses, de acordo com a etnia das pessoas. Os colonizadores implantaram uma agricultura baseada em pequenas propriedades rurais. Eles instituíram cooperativas e associações comunitárias que se estenderam na região. A preservação da cultura e do idioma europeu reforça a identificação com a região. A Igreja se preocupou com esses elementos para a manutenção e fortalecimento do capital social que reflete nas atividades produtivas e no desenvolvimento regional.

Palavras-chave: desenvolvimento local; cooperativismo; preservação cultural.

Abstract: The research analyses the role of the church in building social capital in the western
region of Santa Catarina, South of Brazil. Information was obtained in bibliographical,
documentary and field researches. The Church played an important role in the formation
of colonies in the region and established a model of community and social life that meets
its interests, according to the ethnicity of people. Settlers deployed an agriculture based
on small farming. They started cooperatives and community associations, which spread in
the entire region. Preservation of culture and European language reinforce identification
with the region. The Church is concerned with these elements for the maintenance and
strengthening of social capital reflecting in productive activities and regional development.

Keywords: local development; cooperativism; cultural preservation.

Resumen: La investigación analiza el papel de la Iglesia en la construcción del Capital Social de la región oeste de Santa Catarina. Las informaciones fueron obtenidas en investigaciones bibliográfica, documental y de campo. La Iglesia actuó en la formación de las colonias de la región e instituyó un modelo de vida comunitaria y convivencia social que atendiera sus intereses, de acuerdo con la etnia de las personas. Los colonizadores implantaron una agricultura basada en pequeñas propiedades rurales. Ellos instituyeron cooperativas y asociaciones comunitarias que se extendieron en la región. La preservación de la cultura y del idioma europeo refuerza la identificación con la región. La Iglesia se preocupó con estos elementos para el mantenimiento y fortalecimiento del capital social que refleja en las actividades productivas y en el desarrollo regional.

Palabras clave: desarrollo local; cooperatividad; preservación cultural. 


\section{INTRODUÇÃO}

No início do século XXI, o Brasil viveu um ciclo de crescimento econômico e social marcado pela distribuição de renda e inclusão social. Um dos pilares desse crescimento foi o agronegócio, setor onde a agricultura familiar ganhou força e se consolidou a partir do final dos anos noventa.

A região Sul do Brasil é uma das maiores regiões brasileiras para o agronegócio, baseada essencialmente na produção da agricultura familiar. Nessa região, o oeste de Santa Catarina teve forte influência dos imigrantes italianos e alemães. Instalaram-se devido às condições climáticas e geográficas muito parecidas às suas terras natais. Eles trouxeram consigo a cultura, experiências e conhecimentos adquiridos com seus antepassados. Organizaram suas comunidades conforme estavam acostumados em suas terras de origem. Da insatisfação e revolta perante as difíceis condições de vida e trabalho, desenvolveu-se o cooperativismo, amplamente difundido na região.

Inseridos em uma região pouco desenvolvida e povoada, os habitantes do oeste catarinense recorreram à ação coletiva para o desenvolvimento regional e a valorização de suas produções. As ações conjuntas resultaram em diversas entidades associativas e cooperativas de produção como forma de sustentabilidade e desenvolvimento. Passaram a comercializar a produção excedente e expandir a doutrina associativista em toda a região como um meio de distribuição equitativa de renda e igualdade social.

Nessa região, as propriedades rurais são divididas em comunidades e foram projetadas com uma visão coletiva das famílias, arraigada na ajuda mútua e bem-estar de todos. A religião foi fundamental na formação populacional. Ela foi organizada a partir de descendentes europeus que trouxeram seus hábitos, cultura e conhecimentos voltados à agricultura familiar e ao trabalho cooperativo, amparados pela fé cristã como forma de sobrevivência e desenvolvimento social, cultural e econômico. A colonização da região foi projetada e implantada observando as origens étnicas e a fé religiosa dos novos moradores. Essas características eram entendidas como fundamentais para o desenvolvimento cultural, social e econômico das novas colônias.

Nesse contexto, a pesquisa é orientada pela hipótese de que existe uma grande quantidade de capital social entre os habitantes da região, 
baseado em relações de confiança, ajuda mútua e espírito coletivo e que a religião teve um papel preponderante na implantação desse capital. Diante disso, é possível se perguntar sobre a importância da religião na construção e manutenção desse capital social.

Essa pergunta levou à definição do objetivo da pesquisa, que é de identificar o papel da Igreja na construção do capital social da região oeste de Santa Catarina.

Embora as colônias no oeste de Santa Catarina não tenham sido mantidas totalmente homogêneas em torno da etnia e da religião, muitos descendentes de italianos e alemães preservam suas origens culturais e mantém a fé de seus antepassados por meio da religião e da língua dos países de origem. O cooperativismo se tornou o principal meio de desenvolvimento local e agente articulador das atividades agrícolas e da comercialização dos produtos da região. As relações de cooperação, confiança e ajuda mútua entre agricultores foram construídas sobre os princípios do cooperativismo e estão arraigadas na teia social das comunidades locais. Elas estão presentes na educação e na formação dos produtores rurais, formando a base de sustentação das atividades sociais, econômicas, culturais e ambientais.

Em dezembro de 2013, a Organização das Cooperativas Catarinenses (OCESC) contemplava 254 cooperativas que mantinham mais de 1,6 milhão de pessoas associadas e faturamento anual de $\mathrm{R} \$ 20$ bilhões, ou $11 \%$ do PIB Catarinense. Praticamente a metade das famílias catarinenses estava associada a uma cooperativa (OCESC, 2014).

A Introdução é seguida pela revisão bibliográfica sobre capital social e confiança e pela apresentação da região oeste de Santa Catarina, sua colonização e as atividades econômicas. O item seguinte apresenta a metodologia adotada na pesquisa, seguida dos resultados e análise e, finalmente, das considerações finais.

\section{REVISÃO BIBLIOGRÁFICA}

Esse item apresenta as noções de capital social e confiança, conceitos pesquisados no artigo. 


\subsection{Capital social}

Para Furlanetto (2008), o capital social é a cola que une as instituições e as mantém vinculadas aos cidadãos visando produzir o bem comum. $O$ autor divide o conceito de capital social em duas correntes. A primeira é abordada pelos sociólogos que defendem a ideia de que as ações individuais se fortalecem por meio da participação das pessoas em redes sociais e sua interação com outros atores da rede. A participação em uma rede sólida e duradoura de relações de pessoas gera recursos e benefícios potenciais aos atores. Bourdieu e Coleman pertencem a essa corrente. A segunda corrente, preferida pelos cientistas políticos, considera o capital social como parte significativa das relações e laços internos que formam a base estrutural da ação coletiva e é responsável pela coesão necessária para o alcance de objetivos. Putnam pertence a essa corrente.

Lin (1999) diferencia o capital social individual, entendido como a maneira como as pessoas investem nas relações sociais e captam os recursos disponíveis para obter benefícios e o capital social coletivo, que reforça a coesão social, reproduz e mantém o capital social como um bem coletivo amparado pela confiança, normas e regras. Furlanetto (2008) diferencia o capital social coletivo em três tipos, o comunitário, associado às organizações locais, grupos cívicos e redes informais. O capital social de ponte, que facilita a fluência das informações e possibilita uma localização estratégica das pessoas com acesso a informações diversificadas. E o capital social institucional, que agrega ao capital comunitário e de ponte os aspectos políticos e sociais que dão corpo ao arranjo social.

Para Ávila (2000), os relacionamentos com pessoas próximas, como familiares, vizinhos e membros de uma comunidade criam laços fortes que fortalecem o capital social comunitário. Os relacionamentos com pessoas de outras comunidades são menos intensos e resultam em laços fracos, importantes para a criação do capital social de ponte.

Putnam (2007) define o capital social como um fenômeno social estruturado na associação das pessoas em redes ou outros tipos de organização horizontal com forte presença de confiança mútua e reciprocidade. O capital social mobiliza e capacita as ações coletivas das pessoas para alcançarem objetivos que não conseguiriam se agissem individualmente. 
De acordo com Lin (1999), o capital social está enraizado nas relações e redes sociais, composto por recursos incorporados a uma estrutura social, possíveis de serem acessados e mobilizados por ações intencionais. Nesse contexto, o capital social possui três ingredientes: os recursos incorporados à estrutura social; o acesso aos recursos por pessoas físicas; e o uso ou mobilização desses recursos pelos indivíduos por meio de ações intencionais. O acesso e a utilização dos recursos sociais embutidos nas redes sociais podem melhorar a situação econômica das pessoas.

O Banco Mundial define o capital social como a capacidade de uma sociedade estabelecer laços de confiança e redes de cooperação entre seus membros. A qualidade das relações interpessoais depende das instituições, das relações e normas sociais de uma sociedade. O capital social é o elo que mantém as instituições em contato entre si e vinculadas às pessoas para a produção do bem comum (D`ARAúJO, 2010).

Putnam (2007) constatou que a região norte da Itália era mais desenvolvida e soube usufruir melhor as vantagens da descentralização política em relação à região sul, onde existiam fortes aspectos individualistas. No norte, havia mais envolvimento e cooperação das pessoas com o bem público. Nessa região, o autor identificou grande capacidade de associativismo, cooperação e confiança no governo e entre vizinhos. A cultura cívica e a confiança interpessoal se mostraram recursos indispensáveis para a composição do capital social.

Para medir as diferenças de capital social no Rio Grande do Sul, Bandeira (2003) utilizou indicadores de participação em associações voluntárias (participação em reuniões, exercício de cargos ou funções nessas entidades), redes informais de sociabilidade (visitas a parentes, amigos, vizinhos, atividades de lazer, entre outros) e participação política. Na Serra Gaúcha e no Norte (Planalto), identificou uma grande participação em associações voluntárias, atividades políticas e de sociabilidade informal, que envolve pessoas próximas como amigos e familiares (laços fortes), ou pessoas distantes como conhecidos e colegas (laços fracos). Para o autor, o índice de capital social identificado se deve às raízes coloniais que remontam a imigração e colonização europeia e pelo predomínio da agricultura familiar, aspectos similares à região do oeste de Santa Catarina. Na região metropolitana de Porto Alegre, Bandeira (2003) encontrou um baixo índice 
de capital social, que se deve ao pouco tempo disponível que restringe a possibilidade de vida social e participação em associações voluntárias.

As áreas do Rio Grande do Sul compostas por grandes propriedades (Campanha e Pampa) apresentaram índices de capital social inferiores às demais regiões do Estado (MONASTÉIRO, 2003). Para Bandeira (2003), as raízes históricas das regiões onde predominam as grandes propriedades e a convivência com a escravidão até o final do século XIX podem contribuir com o baixo nível de capital social. Nessas regiões, há predominância de relações sociais marcadas pela hierarquia, uso do poder e dependência. As iniciativas para construir igrejas partiram dos fazendeiros, onde as pessoas e empregados eram convidados a participar nos eventos religiosos, sendo agentes passivos. Por outro lado, nas colônias de descendentes europeus, a estrutura física foi construída por meio da cooperação e mutirões.

As relações e estruturas sociais formadas pela confiança, gerada da combinação das condutas de reciprocidade e cooperação, formam o capital social que proporciona benefícios para as pessoas que mantêm relações (DURSTON, 2002).

\subsection{Confiança}

Para Putnam (2007), sem a confiança o capitalismo não seria viável, pois ela diminui os custos de transações, agiliza os processos e produz melhores resultados. A confiança é o elemento básico do capital social que deriva de duas fontes: das regras de reciprocidade, baseadas na retribuição de favores e na aplicação de regras de constrangimento social para quem não coopera e as infringe; dos sistemas de participação cívica, com a participação em associações comunitárias, clubes esportivos, comunidades religiosas, sindicatos, cooperativas e diversas outras associações que representam possibilidades de cooperação horizontal.

A confiança é uma atitude baseada no comportamento de uma pessoa que participa de uma relação estabelecida. Seu suporte é a cultura e o princípio de reciprocidade. É também um suporte emocional e de afeto pelas pessoas tidas como confiáveis. Essa confiança resulta da repetição das interações sociais conforme as experiências acumuladas e correspondidas por atos de generosidade equivalentes (DURSTON, 2002). 
A reciprocidade é o princípio que rege as relações de uma comunidade. Nas pequenas comunidades, essas relações são estabelecidas por meio de numerosas interações entre as mesmas pessoas, famílias e instituições, sejam elas religiosas, jurídicas, políticas e econômicas. Com isso, a reciprocidade é a base das relações e instituições do capital social (MAUSS, 1990, apud DURSTON, 2002).

Para Ávila (2000), os relacionamentos primários e secundários constituem as características fundamentais de configuração associativa da sociedade. Os relacionamentos primários consistem na cadeia de contatos e vínculos que as pessoas formam gradativamente no decorrer de suas vidas, de maneira espontânea e informal. Esses relacionamentos são mais profundos e intensos, fazendo com que as pessoas se conheçam, se avaliem e se controlem. São laços interpessoais que se consolidam e se expandem no âmbito da vizinhança para os bairros, cidades e assim por diante, possibilitados tanto pelos contatos pessoais diretos como pelos mediados por amigos, parentes, colegas de escola, de profissão, de igreja entre outros. Quanto mais intensos e próximos forem esses relacionamentos na vida das pessoas, mais densos tendem a ser os sentimentos, interesses, objetivos e identidade histórico-cultural das pessoas do local (ÁVILA, 2000).

Os relacionamentos secundários são as regras formais compostas por leis, regimentos, regulamentos e todo tipo de normas e decisões coletivas de controles externos dos indivíduos. Essas regras, quando explicitadas e oficializadas, conferem ao grupo configuração de sociedade. Portanto uma sociedade independente é organizada e regida por relacionamentos secundários e primários (ÁVILA, 2000). O autor afirma que uma comunidade composta por relacionamentos primários em demasia é muito conservadora e fechada. Por outro lado, o excesso de relacionamentos secundários desestrutura a comunidade em termos de sentimentos comuns, interesses, objetivos, identidade com o local e outros laços de coesão.

\section{REGIÃO OESTE DE SANTA CATARINA}

Desde o descobrimento do Brasil, a região oeste de Santa Catarina sempre esteve envolvida em conflitos pela posse de suas terras. No início da colonização, foi disputada por Espanhóis e Portugueses, e mais tarde a 
Argentina reivindicou o domínio do território (KOELLN, 1980; PAIM, 2006). Antes do fim do litígio entre Brasil e Argentina, Santa Catarina solicitou a posse da região, o que revoltou o governo paranaense. Com isso, a área passou a ser chamada de Contestado (BAVARESCO; FRANZEN; FRANZEN, 2013).

Woloszyn (2007) indica que, até o final do século XIX, a região era habitada por comunidades tradicionais, por escravos fugidos do Paraná e Rio Grande do Sul e por luso-brasileiros. Da miscigenação desses grupos étnicos, se originou o caboclo.

Plein (2003), Woloszyn (2007) e Eidt (2011) concordam sobre o fato de a construção da estrada de ferro São Paulo/Rio Grande do Sul, entre 1907 e 1910, ter sido determinante para a colonização do oeste catarinense. Nessa ocasião, foram atraídos para a região cerca de 10.000 trabalhadores de diversas regiões do país. Como forma de concessão, a empresa recebeu do governo $15 \mathrm{~km}$ de terra em cada lado dos trilhos, além do direito de explorar toda a madeira da região. Com isso, assumiu o compromisso de colonizar essas terras. Com o término da construção da estrada em 1910, a empresa repassou para várias empresas colonizadoras a missão de executar o projeto de colonização (PLEIN, 2003; WOLOSZYN, 2007).

Milhares de camponeses foram banidos das terras que ocupavam, pois não possuíam os títulos de propriedade e não produziam para o mercado, conforme a lógica mercantil da república (WOLOSZYN, 2007). A autora indica que, para a exploração da madeira ao longo dos trilhos, a empresa americana utilizou equipamentos de alta tecnologia trazidos da Europa e Estados-Unidos. A maioria da mão de obra era descendente de imigrantes ou estrangeiros contratados de forma permanente. Aos caboclos foram oferecidos trabalhos temporários precários, para o corte e transporte das toras, recebendo seu pagamento por empreitada. Essa precariedade resultou na insatisfação dos interessados e na Guerra do Contestado, que aterrorizou a região de 1912 até 1916, dizimando aproximadamente vinte mil caboclos.

Com o fim da guerra, foram criados os primeiros municípios no oeste catarinense (BAVARESCO; FRANZEN; FRANZEN, 2013). Paim (2006) indica que o crescimento acelerado da população nas colônias gaúchas gerou um excedente populacional, com falta de terras. Em paralelo, o cultivo predador 
realizado com roçadas e queimadas diminuiu a fertilidade das terras. Esses fatores contribuíram para a migração dos descendentes de europeus das velhas colônias gaúchas para o oeste catarinense.

Koelln (1980) destaca que inicialmente duas colônias foram planejadas na bacia do rio Uruguai, Porto Feliz, com descendentes alemães evangélicos, e Porto Novo, com alemães católicos. Ambas deveriam ser homogêneas para evitar a dispersão de forças de desenvolvimento. Após as instalações iniciais e abertura de estradas, mais povoações se constituíram, atraindo outros descendentes de origem europeia, principalmente italianos. Com isso, a região formou sua população mesclando essas duas origens étnicas (KOELLN, 1980).

Onghero (2013) menciona que parte do sucesso da colonização ocorreu devido às relações e a comunicação entre os próprios colonos. Assim que os primeiros colonizadores se instalavam nas propriedades catarinenses, influenciavam seus parentes e amigos a fazerem o mesmo.

Eidt (2011) e Werle (2011) relatam que, desde os primórdios das colônias alemães, existiu escolaridade mínima (ensino básico até a 4ạ série). Esse processo envolveu a comunidade, a Igreja, o professor e a empresa colonizadora. As escolas eram paroquiais ou comunitárias e supriam a ausência de escolas públicas. Geralmente, eram localizadas na igreja. Além da formação moral e intelectual, o professor controlava a vida cotidiana dos alunos, desempenhando um papel estratégico para os propósitos da comunidade, exercendo diversas funções em favor da coesão e imposição das normas sociais.

Bianchezzi (2008) e Eidt (2011) afirmam que Porto Feliz e Porto Novo foram colonizações planejadas em torno da descendência alemã e da religiosidade. Porto Novo teve forte influência dos padres jesuítas, privilegiando os descendentes alemães católicos. Quem não fosse dessa religião e não falasse o idioma europeu não conseguia comprar terras na colônia. Esse modelo atendia ao projeto de colonização dos governantes brasileiros e principalmente da Igreja que perseguia um ideal social com identidade a serviço da religião. Os jesuítas planejavam uma sociedade sem degradação moral, algo que poderia acontecer se houvesse elementos que não fossem da cultura germânica. 
Em 1926, foi criada a colônia de Cascalho, nas margens do rio Uruguai, que abrangia os atuais municípios de Palmitos, Cunha Porã e Maravilha. A empresa colonizadora Companhia Sul Brasil dividiu as terras em colônias de acordo com a etnia e credos religiosos dos novos moradores. Os descendentes de alemães evangélicos foram alocados nas colônias de Palmitos e Cunha Porã, enquanto que os alemães evangélicos que vieram da Rússia se instalaram em Riqueza. Os descendentes de alemães católicos se instalaram em São Carlos e Saudades, cabendo aos italianos as colônias de Caibi (SCHUH, 2011).

Schuh (2011) relata que, no início, a divisão étnica e confessional foi bem administrada pela empresa colonizadora, mas, com o passar dos anos, os proprietários venderam seus lotes sem observar a etnia e a religião do comprador. No início da década de 1950, a colônia de Palmitos já abrigava mais de 80 famílias de descendentes italianos que passaram a predominar no município. O mesmo ocorreu com o município de Riqueza, onde os descendentes italianos predominam atualmente.

\section{METODOLOGIA}

Como método de procedimento, utilizou-se o estudo de caso. Conforme Lakatos e Marconi (2009), o estudo de caso se refere a um levantamento profundo de determinado caso ou grupo humano contemplando todos os seus aspectos. Foi escolhido o método qualitativo, numa pesquisa de caráter exploratória. As informações foram obtidas por meio de pesquisa bibliográfica, documental e por meio de pesquisa de campo, a partir de entrevistas com personalidades locais.

Entrevistas foram conduzidas junto a líderes políticos, como vereadores de Mondaí, São Miguel do Oeste e São João do Oeste, um ex-prefeito de Iporã do Oeste e o secretário da Secretaria de Desenvolvimento Regional (SDR) de Palmitos. Foram obtidas informações em relação ao processo de criação da região, de implantação das associações comunitárias e redes de associações que existem na região, além da formação populacional.

Além de políticos, foram entrevistados dirigentes da Cooperativa A1, especificamente o Gerente da unidade de Mondaí, e um ex-vice-presidente, para obter informações sobre o cooperativismo, os tipos de cooperativas criadas na região e a disseminação dos princípios cooperativistas. Também 
foram ouvidos dois colonizadores que residem em Iporã do Oeste, oriundos da antiga colônia gaúcha Dona Isabel, atual município de Garibaldi. As entrevistas foram realizadas entre os meses de março e julho de 2014.

O papel da Igreja sobre a criação de capital social foi avaliado a partir dos seguintes aspectos:

- Construção de práticas sociais e culturais nas ações das pessoas da região (CASTILHOS, 2001; D’ARAÚJO, 2010) e fortalecimento da cultura cívica e da confiança interpessoal (PUTNAM, 2007).

- Fortalecimento do capital social comunitário, de ponte e institucional (FURLANETTO, 2008; LIN, 1999).

- Construção de normas comuns, com presença de sanções e apoio das autoridades locais (LIN, 1999). Densidade da estrutura social formada por associações (BANDEIRA, 2003);

- Consolidação da solidariedade entre os membros da comunidade (LIN, 1999) e a existência de uma cultura de reciprocidade na região (PUTNAM, 2007);

- Incentivo na criação de redes sociais e na participação dos habitantes (FURLANETTO, 2008; PUTNAM, 2007).

No próximo item são apresentados os resultados da pesquisa.

\section{PAPEL DA IGREJA NA CRIAÇÃO DE CAPITAL SOCIAL}

A Igreja teve papel chave no desenvolvimento do capital social na região oeste de Santa Catarina. As modalidades e os resultados dessa influência são apresentados de acordo com os aspectos identificados na metodologia.

\subsection{Construção de práticas sociais comuns}

Esse item aborda o papel da Igreja na construção de práticas sociais e culturais a partir da colonização da região oeste catarinense, que possibilitou a formação de comunidades com hábitos sociais e culturais comuns em torno da fé religiosa e da etnia.

Com a intensificação do movimento imigratório e o crescimento interno das colônias gaúchas, muitos colonos de etnias europeias migraram para o oeste catarinense, formando colônias cuja economia se estruturou 
na pequena propriedade rural, onde a vida social girava em torno de pequenas vilas. Buscou-se implementar colônias homogêneas, católicas ou luteranas (WERLE, 2011)

Muitos colonizadores da região eram oriundos das mesmas comunidades da serra gaúcha. Como as famílias eram numerosas e as terras insuficientes, houve a necessidade de migrar. Isso fez com que irmãos e vizinhos comprassem áreas próximas e mantivessem as relações de confiança com as mesmas práticas religiosas e sociais a que estavam habituados. A colocação em comunidades homogêneas facilitou a adaptação no território catarinense, uma vez que a heterogeneidade poderia impor dificuldades de convivência, com práticas sociais e religiosas distintas, com o agravante de não dominarem a língua portuguesa.

As empresas colonizadoras eram de caráter religioso e permitiam que cada família pudesse comprar somente uma gleba de terra. Com essa restrição, evitou-se a especulação e o uso das propriedades para fins comerciais. A área era suficiente para a sobrevivência da família, e cada $\mathrm{m}^{2}$ da propriedade devia ser bem aproveitado para impedir desperdícios. As encostas de morros foram preservadas para evitar erosão e esgotamento do solo, o que permitiu a preservação dos rios.

De acordo com a Igreja, somente colônias homogêneas proporcionavam bem-estar material, espiritual e religioso com espírito comunitário (WERLE, 2011). Embora nem todas as comunidades tenham se mantido homogêneas, os costumes, hábitos e a língua europeia foram mantidos. Essas características foram determinantes na manutenção e fortalecimento das práticas sociais e no espírito coletivo das comunidades da região.

Werle (2011) afirma que havia um consenso entre padres e pastores que atuavam nas colônias europeias do Rio Grande do Sul e Santa Catarina, em torno da manutenção das características étnicas e da língua trazida dos países de origem. A aliança entre a fé e o patriotismo era um elemento central para a preservação da religiosidade dos imigrantes, pois padres e pastores acreditavam que, perdendo a língua de origem, facilmente perderiam a fé de seus antepassados.

Esse pensamento permaneceu ao longo dos anos, e a região oeste de Santa Catarina mantém sua estrutura social fortemente ligada à Igreja e às 
etnias europeias. São realizadas anualmente inúmeras festas étnico-culturais que preservam e reforçam as culturas europeias. Os hábitos culturais e as práticas sociais são elementos essenciais na criação e fortalecimento do capital social da região.

\subsection{Fortalecimento do capital social comunitário, de ponte e institucional}

A ausência do Estado deixou as colônias europeias isoladas e possibilitou que a Igreja organizasse as comunidades de acordo com os seus interesses. Os colonizadores eram atraídos por propagandas que elencavam somente os aspectos positivos das terras que estavam sendo vendidas. As dificuldades impostas pelo isolamento e o difícil acesso às terras foram ocultados e se tornaram evidentes quando as famílias já estavam instaladas. Sem estrutura de apoio, os colonizadores iniciaram a construção de suas casas com a ajuda dos vizinhos e construíram seu território com base nas relações sociais. O isolamento e a vida de subsistência contribuíram para a coesão social e o fortalecimento do espírito comunitário (EIDT, 2011; WERLE, 2011).

A derrubada das matas e o plantio das primeiras lavouras foram feitos por meio de mutirões, troca de favores e de produtos de subsistência. 0 espírito comunitário viabilizou a construção das primeiras igrejas, utilizadas para as manifestações religiosas, funcionamento da escola e local de encontros para a realização de atividades sociais e culturais. $O$ isolamento serviu de base para a criação de capital social comunitário. Werle (2011) reforça a importância do trabalho coletivo, que foi determinante para a construção das primeiras igrejas e o fortalecimento do espírito comunitário.

Havia poucos contatos com outras comunidades ou colônias. A visita de padres ou pessoas ligadas às empresas colonizadoras era o único meio de obter informações ou ajuda externa. Por ser a responsável pela colonização da região, a Igreja mantinha relações com as comunidades e realizava um trabalho de auxílio nas colônias europeias do Rio Grande do Sul e Santa Catarina por meio da realização de Congressos Católicos. Esses Congressos eram realizados anualmente e enfatizavam o envolvimento e a participação popular para o funcionamento das instituições comunitárias como escolas, cooperativas e o sistema de crédito. Os eventos também eram organizados 
por jesuítas italianos nas colônias italianas do Rio Grande do Sul e de Santa Catarina (WERLE, 2011).

A realização dos Congressos Católicos reforçou o capital social comunitário e possibilitou, por meio da participação de pessoas de comunidades variadas, de Santa Catarina e do Rio Grande do Sul, a criação de capital social de ponte. Esses relacionamentos permitiram a troca de informações, experiências e conhecimentos em relação à vida comunitária e as atividades produtivas. A Igreja serviu de suporte e orientação para as pessoas com práticas sociais padronizadas, alicerceadas na família e na coletividade. 0 espírito coletivo, arraigado nas práticas sociais, possibilitou a criação de cooperativas e diversas instituições de cunho comunitário. Novas técnicas de produção e comercialização foram desenvolvidas e implementadas, dando uma nova dinâmica social, econômica, produtiva e ambiental para a região. As interações dos segmentos da sociedade com instituições locais de apoio permitiram a criação de capital social institucional.

A ausência quase que total do Estado brasileiro possibilitou ampla liberdade aos jesuítas na organização do espaço, com uma organização social e econômica em torno do cooperativismo e escolarização de acordo com os preceitos religiosos (EIDT, 2011; WERLE, 2011).

A falta de atenção do Estado resultou no abandono e isolamento das colônias, mas permitiu que as comunidades de descendentes europeus mantivessem seus hábitos sociais e culturais. Esse aspecto foi muito importante para o atual nível de desenvolvimento da região oeste de Santa Catarina, que manteve suas características e especificidades locais, determinantes para a instalação e desenvolvimento dos meios produtivos e econômicos. A região se diferencia justamente pelas suas características sociais e culturais, em que os capitais sociais comunitário, de ponte e institucional estão presentes e conduzem as ações cotidianas.

\subsection{Construção de normas comuns}

A estrutura socioeconômica implantada pelos colonos estabeleceu uma sensibilidade religiosa ancorada na normatização da religião institucionalizada. As instituições ligadas à Igreja católica, evangélica e luterana se constituíram nas principais entidades de organização e orientação coletiva 
com a prestação de serviços básicos, como a educação e a saúde (WERLE, 2011).

As práticas e manifestações religiosas se mantêm vivas na região oeste de Santa Catarina. Nos domingos, participar de missas e cultos representa um compromisso social e moral com a própria comunidade, onde no mínimo um membro de cada família se faz presente. Além de um momento de fé, representa um ambiente comunitário baseado nas relações de amizade, em que a vida social e profissional é pautada em conversas informais. É um ambiente para trocar informações, experiências e conhecimentos em relação às atividades produtivas e econômicas.

As normas de conduta estão fortemente ligadas às manifestações religiosas que fomentam os relacionamentos primários. Muitas comunidades rurais católicas mantêm a tradição da "Capelinha" que é transportada diariamente de casa em casa para a reza de um terço com a presença dos vizinhos. Todas as noites, a capelinha representa um momento de devoção, compromisso e encontro com os vizinhos mais próximos. A pequena capela de madeira representa um símbolo religioso e social celebrado por todas as famílias da comunidade, todos os dias do ano.

Para Bianchezzi (2008) e Werle (2011), a Igreja desempenhou um papel normatizador de condutas e integração social, com identidade e costumes próprios. A ausência do Estado interferiu na formação pessoal e educacional das pessoas. Permitiu maior envolvimento da comunidade com a Igreja, na formação moral que orienta a conduta das pessoas de acordo com os preceitos religiosos. Nesse contexto, a conduta e a atitude das pessoas podem facilmente ser antecipadas, o que diminui os custos de transação.

Nas colônias alemãs, os jesuítas estruturaram um sistema escolar interligando a escola e a Igreja. A escola era concebida como um instrumento de formação religiosa para evitar que os filhos dos colonos assumissem os hábitos dos "brasileiros". Eles alegavam que esses últimos frequentavam pouco a igreja e que qualquer chuva ou queda de temperatura era motivo para não ir à missa (WERLE, 2011). As dificuldades impostas pelo clima e o relevo da região não são aceitos como justificativas ou motivos para ausência em compromissos, cujas sansões morais representam a exclusão do grupo 
e a perda de benefícios resultantes da coletividade. Atrasos ou faltas em compromissos não são tolerados.

Bianchezzi (2008) menciona que os agentes religiosos visavam à preservação da língua estrangeira entre os novos moradores. Seus filhos deveriam frequentar escolas que ensinassem alemão para não perder sua fé católica. A Figura 1 representa uma placa localizada na entrada da cidade de São João do Oeste e demonstra a preservação da fé religiosa e das características étnicas.

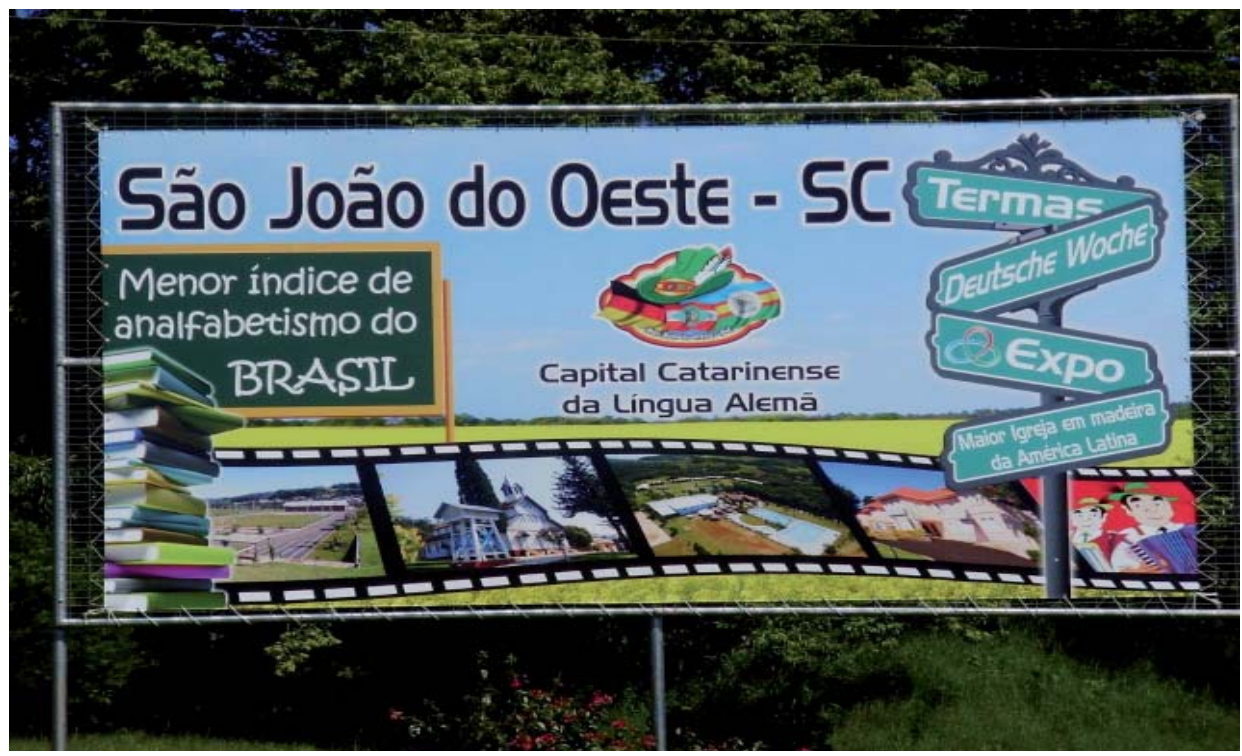

Figura 1- Placa na entrada da cidade de São João do Oeste, região Oeste de Santa Catarina, que enfatiza a língua alemã e a igreja. Foto: Gilson Richter

A cidade de São João do Oeste é considerada a capital catarinense da língua alemã. De acordo com moradores, 93\% das pessoas do município falam alemão, e 97\% entendem a língua germânica. O município realiza a Deutsche Woche, a festa alemã que celebra a cultura alemã. 


\subsection{Fortalecimento da cultura cívica e da confiança interpessoal}

Desde o inicio da colonização, as ações individuais e coletivas estavam sintonizadas com os discursos e práticas dos líderes religiosos. A organização social dos colonos em lotes de terra em formato de espinhas de peixe possibilitou que as famílias vivessem próximas, de maneira a exercer e usufruir constantemente a força dos laços e a confiança interpessoal.

Eidt (2011) ressalta a participação da Igreja na organização dos colonos em comunidades rurais. As comunidades compreendiam entre 70 e 170 famílias de pequenos produtores localizados em torno de uma capela e uma escola. A sociedade foi estruturada na família, no trabalho, na religiosidade e na rigidez das normas morais. O caráter solidário e coletivo foi condição fundamental para o desenvolvimento das famílias do oeste catarinense. Serviu de proteção contra a insegurança e a sobrevivência do tecido social. Esse sentimento se constituiu em valor supremo que sacrificava os interesses particulares em prol da vida comunitária. Desde cedo, as crianças adquirem o espírito coletivo e o hábito da vida comunitária. Ainda em idade escolar ou de catequese, elas são inseridas nos grupos de liturgia e ajudam na leitura de textos bíblicos nas missas e cultos. As comunidades possuem diversas equipes de liturgia organizadas em escalas mensais ou bimestrais. Cada missa ou culto semanal é organizado por uma equipe de liturgia diferente.

Geralmente o grupo de jovens é a primeira associação comunitária em que participa a pessoa. Esses grupos realizam eventos esportivos, culturais e intercâmbios com grupos das comunidades vizinhas, onde são praticadas diversas modalidades de esportes, ou então participam de bailes.

As partidas de futebol entre equipes de comunidades vizinhas são comuns nos domingos à tarde. Para poder participar, há a necessidade de ser sócio do clube esportivo comunitário. Conforme os anos passam, as pessoas exercem seu civismo e se associam em diferentes associações. A partir do casamento e constituição da família, há a "obrigatoriedade" de ser sócio da associação religiosa e conduzir seus filhos no mesmo caminho. Consequentemente, os pais assumem responsabilidades quanto à vida econômica, produtiva e o sustento de sua família. Com isso, há a necessidade de participar das cooperativas de crédito, agropecuárias ou do sindicato 
dos agricultores. Nesse contexto, as práticas coletivas e a participação cívica são transmitidas de geração em geração, criando e fortalecendo o capital social.

O estabelecimento e a manutenção dos laços foram amparados pelos agentes religiosos, com atividades que intensificavam a participação das pessoas na vida coletiva da comunidade e da Igreja, com mecanismos de difusão e normatização. As comunidades se constituíram em um ambiente ideal para o desenvolvimento de laços comunitários com identidade territorial fundamentada na religião e na participação cívica local (WERLE, 2011).

O sistema de Caixas de Créditos Rurais, formado pelas cooperativas do tipo Raiffeisen, disponibilizou recursos financeiros para muitos colonos na compra das terras e foi fundamental para a criação de algumas colônias. Os princípios cooperativistas foram institucionalizados pela Igreja nas comunidades de descendentes europeus e atualmente as cooperativas se constituem como o principal meio de produção e comercialização agropecuária da região.

A participação cívica não se restringe somente às associações comunitárias ou cooperativas. Schmidt (2003) salienta que a participação política de uma comunidade é um forte indicador de existência de capital social. De acordo com um morador da zona rural do município de Iporã do Oeste, os partidos políticos do município possuem um número elevado de filiados. O civismo é demonstrado pela participação das pessoas na política local e estadual. Ele conta com orgulho o fato da comunidade ter conseguido eleger por três mandatos um representante no legislativo municipal. Essa é uma prática comum entre as comunidades rurais para obter representatividade política. Muitas vezes, algumas comunidades se unem em torno de um candidato para ter um representante de sua região.

Um morador entrevistado indicou que situação idêntica ocorre na escolha de representantes para assembleia legislativa estadual, em que a região sempre tem representante, embora a densidade geográfica seja inferior à das demais regiões do Estado. Na câmara federal, o sistema cooperativista catarinense possui representante há várias legislaturas. 


\subsection{Incentivo na criação e participação em redes sociais}

No início do século XX, havia 146 jesuítas alemães no Rio Grande do Sul com o intuito de implementar diversas associações de caráter econômico, social e cultural. Foram criadas cooperativas de crédito e de produção, associações de agricultores e de professores, com participação ativa na colonização de terras e nos Congressos Católicos. Os jesuítas não se preocuparam somente com a vida religiosa dos colonos, mas desenvolveram uma estrutura institucional que abarcou a totalidade das colônias alemãs no Rio Grande do Sul e oeste de Santa Catarina. Para isso, os Congressos Católicos, realizados de 1898 até 1940, foram determinantes. Eles mantinham um canal direto de comunicação com os representantes das colônias em torno de ideias e concepções do mundo social (WERLE, 2011).

Os Congressos Católicos eram realizados anualmente em colônias diferentes, com a participação de representantes de todas as comunidades formadas por descendentes de alemães. Essa prática foi muito importante para incentivar a criação de associações e a participação das pessoas nas redes sociais.

Entre as diversas instituições criadas a partir dos Congressos Católicos, o Sistema de Crédito das Caixas Rurais desempenhou papel fundamental. As cooperativas de crédito rural se espalharam pelo Rio Grande do Sul e oeste de Santa Catarina. O sistema Raiffeisen disponibilizou recursos financeiros para que os jesuítas iniciassem no oeste catarinense a formação de uma colônia homogênea, alemã e católica: Porto Novo (WERLE, 2011).

Nessa colônia, os líderes religiosos implantaram um modelo social baseado no associativismo comunitário estruturado nas redes de relacionamentos. Os agentes religiosos doutrinavam a participação em associações e o cooperativismo para manter o espírito comunitário, aspectos necessários para o desenvolvimento econômico baseado em princípios étnicos. Os jesuítas coordenavam todas as ações na vida social das pessoas. Promoviam o cooperativismo e o aumento da produtividade utilizando técnicas agrícolas (BIANCHEZZI, 2008).

As comunidades rurais da região oeste estão amarradas por diversas associações que formam nós de relacionamentos em redes sociais. Em uma mesma comunidade, é possível encontrar diversas associações com ampla 
participação das pessoas. A associação religiosa, o clube esportivo, o grupo de jovens, o clube de mães (jogo de bolãozinho), a associação comunitária de moradores são exemplos de associações existentes numa comunidade e que formam um denso tecido social. Além dessas associações, as pessoas participam de cooperativas, associação de produtores, sindicato dos trabaIhadores rurais, Centros de tradição Gaúcha (CTG), entre outros.

Para arrecadar fundos e manter a sustentabilidade financeira das entidades, cada associação realiza suas festas e eventos. Para que haja organização e êxito na realização desses eventos, em cada início de ano, os líderes das associações comunitárias se reúnem na sede do município e definem um calendário com as datas de todos os eventos festivos do município. 0 objetivo é evitar a realização de eventos na mesma data em comunidades próximas. Quando alguma comunidade quer realizar um evento, e a data não consta no calendário, a Polícia Civil não libera a licença para realizá-lo. Com esse calendário, cada associação adquiriu o direito da data, e as festas e bailes se tornaram tradicionais. Essa programação limita o número de festas e bailes na mesma data e faz com que as comunidades participem e prestigiem os eventos das comunidades vizinhas.

Após os cultos ou missas realizados aos domingos pela manhã, são disputadas partidas de futebol entre clubes ou equipes de comunidades vizinhas. Após as partidas, é servido o almoço e, à tarde, acontecem outros jogos de futebol e reunião dançante, conhecida como "matiné". A comunidade que realiza o evento assume o compromisso de retribuir a visita quando a comunidade vizinha realiza seu evento.

\section{CONSIDERAÇÕES FINAIS}

Desde a formação das primeiras colônias europeias no Rio Grande do Sul, a Igreja se envolveu na vida social das comunidades, com o objetivo de manter a fé religiosa e orientar a conduta das pessoas em torno da família e dos princípios éticos. Diferentemente do Estado gaúcho, cujo Governo se preocupou com as colônias europeias, o Governo catarinense se omitiu e não ofereceu ajuda aos colonizadores. Esse descaso facilitou a atuação dos religiosos na criação e controle de colônias homogêneas na região oeste do estado. 
A manutenção da cultura e das práticas sociais entre os descendentes europeus fortaleceu a coletividade e o espírito associativista trazido pelos colonizadores. Como resultado, a região oeste de Santa Catarina está inserida num ambiente produtivo e econômico amplamente estruturado em associações e cooperativas que impõem uma dinâmica territorial própria. As relações interpessoais, a confiança e a reciprocidade estão fortemente vinculadas à atuação das instituições religiosas. Ainda hoje a Igreja continua sendo um dos alicerces da estrutura social e um elemento articulador da sociedade civil organizada.

Atualmente, é possível criticar o papel da Igreja na formação das colônias dessa região, em função dos novos valores sociais. Pode haver dificuldades para entender os motivos que a levou a agir e organizar as comunidades rurais em função de seus interesses. É também possível criticar o sentimento patriótico e de pertencimento das pessoas em um território construído pelos hábitos culturais, étnicos e religiosos.

No entanto é difícil se colocar no lugar dos colonizadores e dos próprios agentes religiosos que viveram numa época em que a realidade não Ihes permitia alternativas. Sua preocupação com os valores sociais e a conduta das pessoas estava alicerceados na família e na vida comunitária. É notório que, mesmo que as colônias não tenham se mantido homogêneas, o projeto religioso constitui a base da sociedade da região oeste catarinense e é o principal responsável pela criação, fortalecimento e estoque de capital social.

A partir dos resultados obtidos neste trabalho, pode-se concluir que a Igreja contribuiu para a existência do capital social da região oeste de Santa Catarina. A pesquisa focou basicamente a área rural, porém a região é formada por pequenos municípios em que é difícil visualizar os limites das áreas urbanas e rurais, devido à proximidade relacional e as interações existentes entre as pessoas da mesma origem ou religião. Nas áreas urbanas, a vida comunitária também se baseia nas relações entre as pessoas e na participação cívica em associações, com grande influência da Igreja.

Para trabalhos futuros, pode-se expandir a pesquisa para as demais regiões do Estado, comparar o capital social existente e o seu papel no desenvolvimento das regiões. Essa evidência de capital social pode ser útil 
para a elaboração e implementação de políticas públicas específicas para cada região, respeitando as diferenças regionais e as especificidades de cada território. Por último, o mesmo estudo pode ser realizado nas regiões do Rio Grande do Sul colonizadas por descendentes europeus, comparando a evolução desses dois territórios que possuem a mesma base populacional.

\section{REFERÊNCIAS}

ÁVILA, V. F. Pressupostos para formação educacional em desenvolvimento local. Interações - Revista Internacional de Desenvolvimento Local, Campo Grande, MS, v. I, n. 1, p. 63-76, 2000.

BANDEIRA, P. S. Algumas hipóteses sobre as causas de diferenças regionais quanto ao capital social no Rio Grande do Sul. In: CORREA, S. M. de S. (Org.). Capital social e desenvolvimento regional. Santa Cruz do Sul: EDUNISC, 2003.

BAVARESCO, P. R.; FRANZEN, D. O.; FRANZEN, T. E. Políticas de colonização do extremo oeste catarinense e seus reflexos na formação da sociedade regional. Revista Trilhas da História, Três Lagoas, v. 3, n. 5 jul./dez., p. 86-104, 2013.

BIANCHEZZI, C. Imigrantes de origem alemã e a presença da igreja católica em Santa Catarina. In: ENCONTRO REGIONAL DE HISTÓRIA: PODER, VIOLÊNCIA E EXCLUSÃO, 19., São Paulo, 8-12 set. 2008. Anais... São Paulo: ANPUH/SP; USP, 2008.

CASTILHOS, D. S. B de. Capital social e políticas públicas: um estudo da linha infraestrutura e serviços aos municípios do Programa Nacional de Fortalecimento da Agricultura Familiar. 2001. Porto Alegre: Dissertação (Mestrado em Desenvolvimento Rural)- Universidade Federal do Rio Grande do Sul, RS, 2001.

D’ARAÚJO, M. C. Capital social. 2. ed. Rio de Janeiro: Zahad, 2010.

DURSTON, J. El capital social campesino en la gestion del desarrollo rural: díadas, equipos, puentes y escaleras. Díadas, equipo, puentes y escaleras. Santiago de Chile: Comisión Económica para America Latina y Caribe (CEPAL), 2002.

EIDT, P. Projeto Porto Novo: utopia ou etnocentrismo? Revista Esboços, Florianópolis, v. 18, n. 25, p. 184-211, 2011.

FURLANETTO, E. L. Instituições e desenvolvimento econômico: a importância do capital social. Revista de Sociologia Política, Curitiba, v. 16. supl., p. 55-67, (2008).

KOELLN, A. Porto Feliz: a história de uma colonização às margens do rio Uruguai. Mondai: Coordenadoria Municipal de Ensino, 1980.

LAKATOS, E. M.; MARCONI, M. de A. Metodologia científica. 5. ed. São Paulo: Atlas, 2009. 
LIN, N. Building a Network Theory of Capital Social. Connections, v. 22, n. 1, p. 29-51, 1999.

MONASTÉIRO, L. M. Medindo o capital social: uma análise das regiões do Rio Grande do Sul. In: CORREA, S. M. de S. (Org.). Capital social e desenvolvimento regional. Santa Cruz do Sul: EDUNISC, 2003.

ONGHERO, A. L. Colonização e constituição do espaço rural no oeste de Santa Catarina. In: SIMPÓSIO NACIONAL DE HISTÓRIA, 27., Natal, 22-26 jul. 2013. Anais.... Natal, RN: ANPUH; UFRN, 2013. Disponível em: <http://www.snh2013.anpuh.org/ resources/anais/27/1364480403_ARQUIVO_AndreLuizOngheroartigoANPUH2013. pdf>. Acesso em: 12 jun. 2014.

ORGANIZAÇÃO DAS COOPERATIVAS DO ESTADO DE SANTA CATARINA (OCESC). Cooperativas catarinenses crescerão 15\% nesse ano. 2014. Disponível em: <http:// www.ocesc.org.br/noticias_e eentos/noticias_eventos.php?id=9548>. Acesso em: 5 out. 2014.

PAIM, E. A. Aspectos da constituição histórica da região oeste de Santa Catarina. Saeculum- Revista de História, João Pessoa, n. 14, jan./jun. 2006. Disponível em: <http://www.okara.ufpb.br/ojs/index.php/srh/articl /viewFile/11346/6460>. Acesso em: 27 jun. 2015.

PLEIN, C. As metamorfoses da agricultura familiar: o caso do município de Iporã do Oeste, Santa Catarina. 2003. Dissertação ( Mestrado em Desenvolvimento Rural) - Universidade Federal do Rio Grande do Sul (UFRGS), Porto Alegre, RS, 2003.

PUTNAM, R. D. Comunidade e democracia: a experiência da Itália moderna. $1^{\circ}$ reimp. Rio de Janeiro: Editora FGV, 2007.

SCHMIDT, J. P. Capital social e participação política em Santa Cruz do Sul. In: CORREA, S. M. S. (Org.). Capital social e desenvolvimento regional. Santa Cruz do SUl, RS: EDUNISC, 2003.

$\mathrm{SCHUH}, \mathrm{M}$. B. Histórias da colonização de Palmitos. Chapecó: CEOM/Unochapecó, 2011. (Coleção Histórias Locais, v. 6).

WERLE, A. C. Porto Novo: o reino jesuítico germânico no oeste de Santa Catarina. Curitiba: CRV, 2011.

WOLOSZYN, N. Em busca da terra: colonização e exploração de madeiras no oeste Catarinense. In: CONGRESSO INTERNACIONAL DE EDUCAÇÃO, 4., [s.d.], Concórdia, 2007. Anais... Concórdia, SC: Universidade do Contestado, 2007. [CD-ROM]. 